\section{OPEN ACCESS}

Edited by:

Jaye Chin-Dusting,

Monash University, Australia

Reviewed by:

Marianne Tare,

Monash University, Australia Aida Salameh,

Leipzig University, Germany

${ }^{*}$ Correspondence:

Wing Tak Wong

jack_wong@cuhk.edu.hk

Gary Tse

tseg@cuhk.edu.hk

Specialty section:

This article was submitted to Integrative Physiology,

a section of the journal

Frontiers in Physiology

Received: 29 July 2016 Accepted: 16 November 2016 Published: 06 December 2016

Citation

Wong P, Tan T, Chan C, Laxton V, Chan YWF, Liu T, Wong WT and Tse G

(2016) The Role of Connexins in

Wound Healing and Repair: Novel

Therapeutic Approaches

Front. Physiol. 7:596.

doi: 10.3389/fphys.2016.00596

\title{
The Role of Connexins in Wound Healing and Repair: Novel Therapeutic Approaches
}

\begin{abstract}
Pui Wong ${ }^{1}$, Teresa Tan ${ }^{2}$, Catherine Chan ${ }^{2}$, Victoria Laxton ${ }^{3}$, Yin Wah Fiona Chan ${ }^{4}$, Tong Liu ${ }^{5}$, Wing Tak Wong ${ }^{6 *}$ and Gary Tse ${ }^{7,8 *}$

${ }^{1}$ Li Ka Shing Faculty of Medicine, School of Biomedical Sciences, University of Hong Kong, Hong Kong, Hong Kong, ${ }^{2}$ Department of Surgery, Faculty of Medicine, Chinese University of Hong Kong, Hong Kong, Hong Kong, ${ }^{3}$ Intensive Care Department, Royal Brompton and Harefield NHS Foundation Trust, London, UK, ${ }^{4}$ Department of Psychology, School of Biological Sciences, University of Cambridge, Cambridge, UK, ${ }^{5}$ Tianjin Key Laboratory of Ionic-Molecular Function of Cardiovascular Disease, Department of Cardiology, Tianjin Institute of Cardiology, Second Hospital of Tianjin Medical University, Tianjin, China, ${ }^{6}$ School of Life Sciences, Chinese University of Hong Kong, Hong Kong, Hong Kong, ${ }^{7}$ Department of Medicine and Therapeutics, Faculty of Medicine, Chinese University of Hong Kong, Hong Kong, Hong Kong, ${ }^{8}$ Faculty of Medicine, Li Ka Shing Institute of Health Sciences, Chinese University of Hong Kong, Hong Kong, Hong Kong
\end{abstract}

Gap junctions are intercellular proteins responsible for mediating both electrical and biochemical coupling through the exchange of ions, second messengers and small metabolites. They consist of two connexons, with (one) connexon supplied by each cell. A connexon is a hexamer of connexins and currently more than 20 connexin isoforms have been described in the literature thus far. Connexins have a short half-life, and therefore gap junction remodeling constantly occurs with a high turnover rate. Post-translational modification, such as phosphorylation, can modify their channel activities. In this article, the roles of connexins in wound healing and repair are reviewed. Novel strategies for modulating the function or expression of connexins, such as the use of antisense technology, synthetic mimetic peptides and bioactive materials for the treatment of skin wounds, diabetic and pressure ulcers as well as cornea wounds, are considered.

Keywords: gap junctions, connexins, antisense oligodeoxynucleotides, connexin mimetic peptides, gap junction modulators, wound healing, wound repair

\section{INTRODUCTION}

Gap junctions are intercellular channels that mediate both electrical and biochemical coupling through the exchange of ions, second messengers, and small metabolites (Kanno and Loewenstein, 1964; Lawrence et al., 1978). Gap junction intercellular communication (GJIC) is essential for the regulation of cellular differentiation and apoptosis, movement of cells within tissues, and intracellular signaling (Zhou and Jiang, 2014). In excitable tissues, GJIC also governs the conduction of electrical signals between successive cells (Koval et al., 2014; Veeraraghavan et al., 2014, 2015; Tse, 2016; Tse et al., 2016a). A gap junction is formed by two connexons, where one is provided by each cell (Harris, 2001). Each connexon is a hexamer of connexins (Cx). Currently 21 members of the human connexin gene family have been identified (Söhl and Willecke, 2004).

Some connexin isoforms are cell-type specific, and their expression is induced by different metabolic states, such as pluripotent stem cell induction (Ke et al., 2013), epidermal wound healing (Becker et al., 2012), epithelial-to-mesenchymal transition (EMT) (Zhou and Jiang, 2014), and pathological states such as hepatitis (Crespo Yanguas et al., 2016). Connexins can be found in 
both excitable and non-excitable tissues with different spatiotemporal patterns. For example, the cardiac myocardium has abundant expression of the isoforms $\mathrm{Cx} 30.2, \mathrm{Cx} 40, \mathrm{Cx} 43$, and Cx45 (Davis et al., 1995; Jongsma, 2000; Tse and Yeo, 2015). Their expression levels vary between different cardiac regions: $\mathrm{Cx} 40$ is only expressed in the atria; whereas in the ventricles Cx43 is extensively expressed with minimal levels of Cx40. During cardiac development, Cx45 levels are progressively downregulated (Alcoléa et al., 1999). In non-excitable tissue, Cx43 can be found in breasts, kidneys, skin and lungs; Cx26 is expressed in liver, kidneys and oesophageal epithelium, and Cx32 is found in liver and kidneys (Wilgenbus et al., 1992; Goldberg et al., 2004).

Gap junctions operate through two distinct gating mechanisms: membrane voltage-dependent and transjunctional voltage-dependent gating (also known as fast and slow gating; Bukauskas and Verselis, 2004). Besides voltage sensitivity, both mechanosensitivity and chemosensitivity have been reported (Bao et al., 2004; Bukauskas and Verselis, 2004). Connexin activity is influenced by intracellular $\mathrm{Ca}^{2+}, \mathrm{pH}$, chemical uncouplers (Tse et al., 2016b,c,d,e,f), phosphorylation events (Musil and Goodenough, 1991; Bennett and Verselis, 1992), and lipid availability in the immediate environment, including low-density lipoprotein, apolipoprotein-B (Meyer et al., 1991) and cholesterol (Meyer et al., 1990). Gap junctions allow the passive diffusion of ions, intracellular molecules that include metabolites and messengers such as cyclic AMP, cyclic GMP and $\mathrm{IP}_{3}$. Undocked connexons are not inactive, but can participate in intracellular signaling (Evans et al., 2006). Transient opening of connexons can permit entry of extracellularly released molecules during cellular stress (Froger et al., 2010), whereas prolonged opening may initiate cell death pathways.

In recent years, there has been growing interest in the role of connexins and therapeutic usage of gap junction modulators in various clinical conditions (O'Carroll et al., 2013). As well as modifying gap junction function, other different interventions can alter the synthesis, transport, assembly, phosphorylation, and degradation of gap junction proteins (Beyer and Berthoud, 2002). Gene therapy can restore or increase GJIC in transfected cells and "knock-in" animals (Plum et al., 2000; Beyer and Berthoud,
2002). The different treatment options in the experimental stages are presented in Table 1. This article will focus on the roles of gap junctions in wound healing while also discussing potential directions for further investigation and treatment development.

\section{SKIN WOUND HEALING}

The integumentary system is the largest system of the body and maintenance of its integrity is critical to survival of the organism. A number of connexins can be found in the skin, including Cx26, 30, 30.3, 31, 31.1, 32, 37, 40, 43, and 45. An overview of the $\mathrm{Cx}$ expression patterns in the different skin layers is presented in Figure 1. $\mathrm{Cx} 43$, the predominant isoform found in skin, is mainly expressed in the strata spinosum and basale, whereas Cx26 is detected in the basal layers and upper stratum spinosum (Wiszniewski et al., 2000; Wang et al., 2010). Of these, $\mathrm{Cx} 43$ localizes to the skin vasulature, fibroblasts, dermal appendages and the basal and lower spinous layers (MendozaNaranjo et al., 2012), It can interact with different components in tight and adherens junctions (Scott et al., 2012). Tight junctions are made of proteins such as zona occludens-1 and -2 (ZO$1, \mathrm{ZO}-2)$, and have a barrier function to prevent passage of molecules and ions between plasma membranes of adjacent cells (Kirschner and Brandner, 2012). Cx43 interacts with ZO-1 and -2 in a cell cycle phase-specific manner, thereby regulating cell growth, differentiation, migration, and proliferation (Singh et al., 2005).

Skin wound healing, which occurs in response to injury, involves a complex interplay of physiological processes (Bajpai et al., 2009). Optimal wound healing can be divided into the following four stages of hemostasis, inflammation, proliferation and maturation. Angiogenesis, re-epithelialization and collagen repair are essential, taking place mainly during the latter part of wound healing, proliferation and maturation stages (Guo and Dipietro, 2010). Connexins are present in both the dermis and epidermis (Ghatnekar et al., 2009), with the exception of the uppermost layer of the epidermis, the stratum corneum (Caputo and Peluchetti, 1977; Scott et al., 2012). The distribution of connexin isoforms varies throughout the epidermis, and

\section{TABLE 1 | Vehicles used include Pluronic Gel and microcapsules.}

\begin{tabular}{|c|c|c|c|c|}
\hline Class & Mechanism & Examples & Disease & References \\
\hline $\begin{array}{l}\text { Antisense } \\
\text { oligodeoxynucleotides }\end{array}$ & $\begin{array}{l}\text { Binding to messenger RNA } \\
\text { encoding for connexins }\end{array}$ & $\begin{array}{l}\text { Cx43-specific antisense oligodeoxynucleotides } \\
\text { (Cx43 AsODN) }\end{array}$ & Skin wound healing & $\begin{array}{l}\text { Qiu et al., 2003; Mori et al., } \\
\text { 2006; O'Carroll et al., } 2013\end{array}$ \\
\hline \multirow[t]{2}{*}{$\begin{array}{l}\text { Connexin mimetic } \\
\text { peptides }\end{array}$} & Direct binding to connexins & $\alpha \mathrm{CT} 1$ & $\begin{array}{l}\text { Skin wound healing; Diabetic foot } \\
\text { ulcers; venous leg ulcers; corneal } \\
\text { wound healing }\end{array}$ & $\begin{array}{l}\text { Moore et al., 2013; Grek } \\
\text { et al., 2014, 2015; } \\
\text { Ghatnekar et al., } 2015\end{array}$ \\
\hline & & Gap27 & $\begin{array}{l}\text { Skin wound healing; pressure } \\
\text { ulcers; Diabetic foot ulcers }\end{array}$ & $\begin{array}{l}\text { Evans and Boitano, 2001; } \\
\text { Pollok et al., } 2011\end{array}$ \\
\hline Biomaterials & $\begin{array}{l}\text { Alteration of gap junction } \\
\text { behavior, and upregulation } \\
\text { of growth factors }\end{array}$ & Bioactive glass & Skin wound healing & Li et al., 2016 \\
\hline
\end{tabular}




\section{Localization of Gap Junction Proteins in Human Epidermal layer}

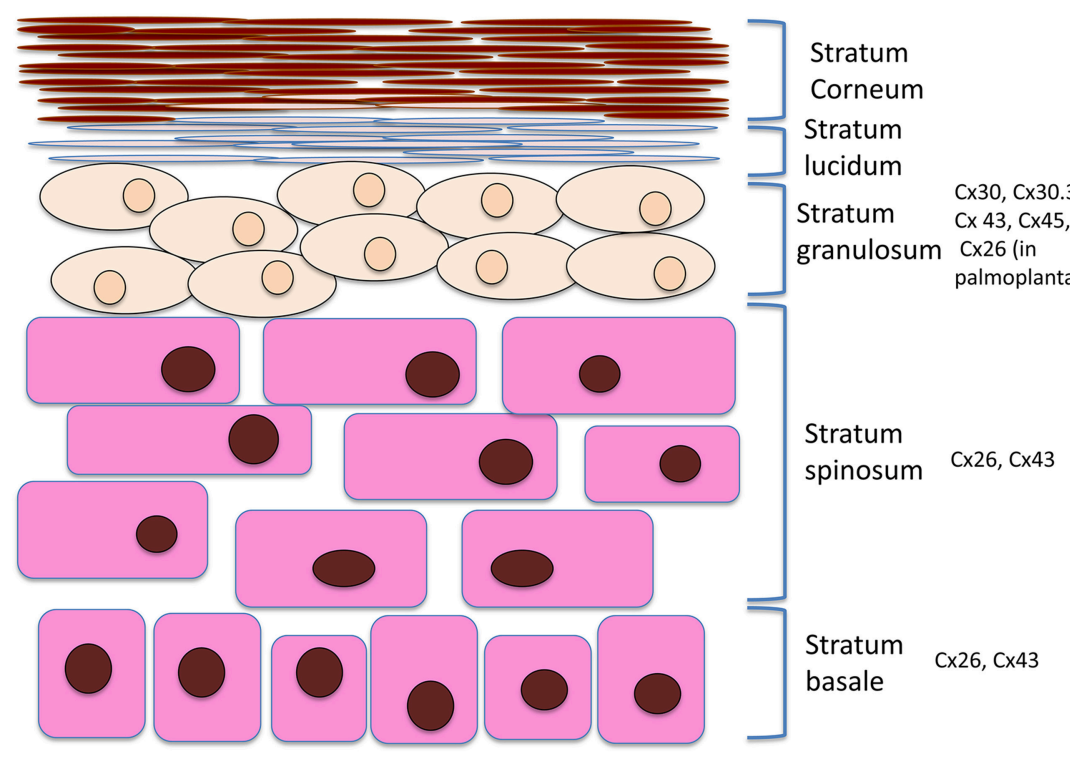

FIGURE 1 | Distribution of different connexin isoforms in different layers of the skin.

potentially plays a role in regulating keratinocyte differentiation (Brissette et al., 1994; Lucke et al., 1999). Inflammatory and growth factors can pass through gap junctions to exert their effects on target sites.

$\mathrm{Cx} 43$ downregulation is associated with increased angiogenesis, migration of fibroblasts and multiplication of keratinocytes as well as reduced infiltration of immune cells (Grek et al., 2014) (Figure 2). These effects are mediated by the upregulation of transforming growth factor-beta (TGF- $\beta$ ) and collagen $\alpha 1$, and the downregulation of the inflammatory mediators, chemokine (C-C motif) ligand 2 (CCL2) and tumor necrosis factor-alpha (TNF- $\alpha$ ) (Grek et al., 2015). TGF- $\beta 3$ is of interest as it has been shown to accelerate wound healing time and scarring, which was associated with decreased $\mathrm{Cx} 43$ (Jin et al., 2008). TGF- $\beta 1$ is closely associated with skin wound healing; its expression is upregulated in a fibroblast woundhealing model involving Cx43 knockdown (Mori et al., 2006). For example, in an autosomal dominant disorder termed oculodentodigital dysplasia (ODDD), skin manifestations are associated with over 70 mutations in the $\mathrm{Cx} 43$ gene (GJA1) (Esseltine et al., 2015). In a mouse model with a G60S mutation in GJA1, a delay in wound closure compared to wild-type littermates is observed, which is likely to be due to defects in the dermal fibroblasts. Indeed, in dermal fibroblasts obtained from patients with ODDD, GJIC is reduced (Churko et al., 2011).

$\mathrm{Cx} 43$ proteins can exist in multiple phosphorylated forms (Budunova et al., 1994; Kuroki et al., 1998). Serine phosphorylation of the C-terminal can alter channel gating, thereby regulating GJIC (Márquez-Rosado et al., 2012). For example, S373 phosphorylation disrupts Cx43 interaction with ZO-1, which promoted Cx43 accumulation and assembly into larger gap junctions, in turn enhancing GJIC (Solan and Lampe, 2014). TPA enhances $C x 43$ phosphorylation on the S368 residue via PKC (Márquez-Rosado et al., 2012). Consequently, reduced channel conductance and GJIC were observed (Lampe et al., 2000; Solan et al., 2003). Other post-translational modification events can be exemplified by S279/282 phosphorylation leading to gap junction closure (Lin et al., 2001). S368 phosphorylation of $\mathrm{Cx} 43$ in the basal cell compartment, which peaks at $24 \mathrm{~h}$ (Márquez-Rosado et al., 2012), led to reduced GJIC and enhanced migration of keratinocytes (Richards et al., 2004). The phosphorylation levels return to baseline at $72 \mathrm{~h}$ after initial skin injury. Cx43 phosphorylation and TGF- $\beta 1$ also contribute to the transformation of fibroblasts into myofibroblasts, which are responsible for wound contraction and thus improved healing results (Churko and Laird, 2013). These findings demonstrate therapeutic potential in regulation of $\mathrm{Cx} 43$ through modulating upstream pathways responsible for $\mathrm{Cx} 43$ phosphorylation at different amino acid residues. However, to fulfill its full therapeutic potential for adequate design of kinase-targeting drugs, a deeper knowledge of the kinase system is required (Solan and Lampe, 2014).

Different spatio-temporal patterns of connexins expression have been observed in various stages of wound healing (Figure 3; Coutinho et al., 2003; Brandner et al., 2004). Initially, all connexins are downregulated in response to wounding (Coutinho et al., 2003). In mouse models, Cx26 and Cx30 are upregulated in epidermal cells proximal to the wound, but are downregulated in cells around the edge (Coutinho et al., 2003; Becker et al., 2012). A similar pattern was found in human cutaneous wound healing, with initial absence of staining of $\mathrm{Cx} 26, \mathrm{Cx} 30$, and $\mathrm{Cx} 43$ around the wound site (Brandner et al., 
2004). This altered distribution pattern is most pronounced at $24 \mathrm{~h}$. At the later resolution stage, Cx26 remains abundantly expressed, whereas $\mathrm{Cx} 31.1$ and $\mathrm{Cx} 43$ returns to normal prewounded levels (Goliger and Paul, 1995; Brandner et al., 2004; Becker et al., 2012).

A number of approaches can be used to alter gap junctions. The first is antisense technology. Cx43-specific antisense oligodeoxynucleotides ( $\mathrm{Cx} 43$ AsODN) incorporated into Pluronic Gel have been tested on cutaneous wounds. The Pluronic Gel consists of both aqueous and organic phases within a micellar network and can efficiently partition with the skin, facilitating transport of pharmacological active substances across the skin. This approach led to suppression of Cx43 expression and improvements in both the rate and quality of healing (Qiu et al., 2003; Mori et al., 2006). The most commonly used AsODN is an ssDNA that consists of 30 deoxynucleotides with an unmodified backbone (O'Carroll et al., 2013). This allows direct inhibition of $\mathrm{Cx} 43$ translation by complementary binding to the messenger RNA, hence depleting the cells of $\mathrm{Cx} 43$. As a result, the level drops since it is being continuously degraded by proteasomes. Multiple events findings were noted as a consequence: (1) inflammatory response attenuation; (2) enhanced myofibroblast differentiation and wound contraction; (3) increased keratinocyte proliferation; (4) fibroblast migration; (5) increased rate of angiogenesis (6) improved re-epithelialization and granulation tissue formation (Figure 2). On a macroscopic level, the wounds demonstrated a reduction in inflammation and exudation (Qiu et al., 2003). Neutrophil infiltration is part of the immune response against potential pathogen invasion of the wound site, but may also delay wound closure (Dovi et al., 2003). Cx43 AsODN treatment led to reductions in the number of neutrophils and levels of cytokines such as TNF- $\alpha$ and CCL2 at the injury site, and may accelerate epidermal healing (Rossi and Zlotnik, 2000). Loss of Cx43 increases the speed of wound closure (Kretz et al., 2003; Qiu et al., 2003). This may favor keratinocyte mobilization, proliferation and transformation into a migratory phenotype. However, re-expression of $\mathrm{Cx} 43$ is important in post-wound stages. Therefore, the importance of time-dependent regulation of gap junction expression during wound healing should be recognized.

Another approach to alter gap junction function is the application of mimetic peptides. These are synthetic compounds with sequence homologies to a short conserved extracellular loop domain of connexins (Desplantez et al., 2012), and can reversibly inhibit GJIC (O'Carroll et al., 2013). An example is the alpha-carboxy terminus $1(\alpha \mathrm{CT} 1)$, which can inhibit $\mathrm{Cx} 43$ by competitive binding to ZO-1 (Grek et al., 2014). This agent is known to promote cellular uptake, reduce fibrosis and modulate wound-healing response to implants (Ghatnekar et al., 2009; Soder et al., 2009), in turn enhancing GJIC. Under physiological conditions, the binding of the partner proteins is associated with gap junction remodeling and cellular communication during wound healing (Soder et al., 2009).

Acute application of $\alpha \mathrm{CT} 1$ at the implant site produced therapeutic effects similar to those of $\mathrm{Cx} 43$ AsODN, including reduced neutrophil recruitment, increased tissue capsule vascularity and decreased fibrosis (Soder et al., 2009; Grek et al.,

\section{Skin injury and connexin 43}

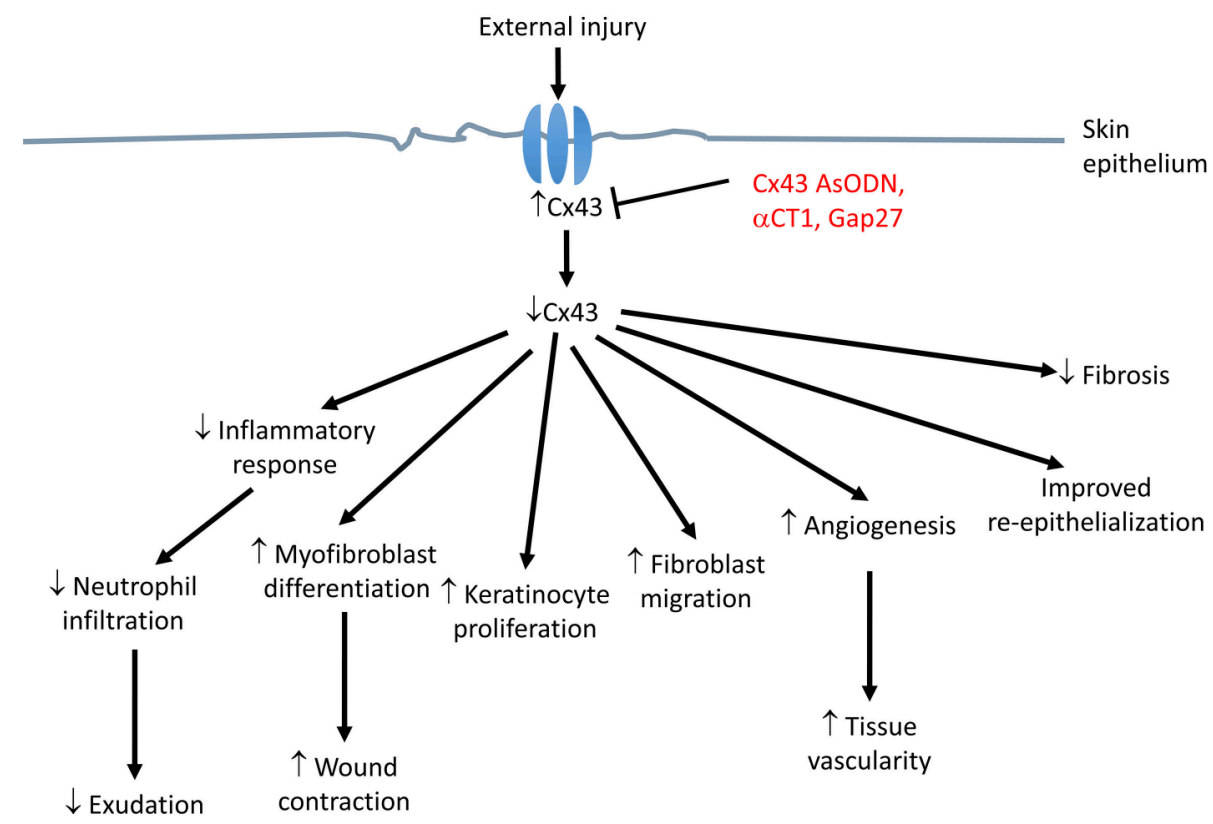

FIGURE 2 | The role of connexin 43 in skin wound healing in response to injury. 


\title{
Temporal and spatial patterns of connexins in cutaneous wound healing
}

\author{
Time after initial \\ wounding \\ Cx26, $\mathrm{Cx} 30$ \\ Type of Connexin \\ 0 hours \\ Weak and sporadic expression of in \\ stratum granulosum \\ Found in all viable layers \\ (lowest in stratum basale, \\ highest in upper stratum spinosum) \\ 5 hours \\ Decrease in expression \\ 18 hours \\ Weak upregulation near wound margins \\ and basal cell layers, \\ Undetected in close surrounding cells and \\ regenerating epidermis \\ 24-48 hours \\ Variable expression in different layers at \\ and near wound margins and \\ regenerating epidermis \\ Present at some distance from the wound \\ Absent at and near wound margins and in \\ regenerating epidermis \\ Absent in leading edges of regenerating \\ epidermis \\ 5-6 days \\ Low levels in all cell layers of central \\ wound areas, near and at some \\ distance from wound \\ Absent at and near wound margins and \\ regenerating epidermis

Absent in leading edges of regenerating
epidermis \\ Incorporated from: \\ Connexins 26, 30, and 43: differences among spontaneous, chronic, and accelerated \\ human wound healing. Brandner JM(1), Houdek P, Hüsing B, Kaiser C, Moll I. \\ Comment in J Invest Dermatol. 2004 May;122(5):IX-X. \\ Low levels in regenerated epidermis \\ High expression in epidermis at some \\ distance from wound
}

FIGURE 3 | Temporal and spatial patterns of connexins in cutaneous wound healing. Information derived from Brandner et al. (2004).

2014). Currently, clinical trials are being conducted to examine the effects of a topical formulation of $\alpha \mathrm{CT} 1$ in laparoscopic surgical wounds, diabetic foot and venous leg ulcers. There are some mild reversible side effects above the maximum tolerated dose, such as piloerection, weakness, abnormal gait and breathing patterns (Grek et al., 2014). Cx43 knockout in mice led to altered expression of multiple testicular genes (Giese et al., 2012) and Cx43 in bone marrow plays an important role in hematopoietic regeneration (Presley et al., 2005). Therefore, tissue-specific targeting of connexins is needed to prevent side effects affecting other systems for successful clinical applications in the future. Non-pharmacological approaches such as the use of biomaterials have also been shown to improve wound healing. For example, bioactive glass enhances wound healing via different mechanisms. It contains ion extracts that can reduce the open probability of hemi-channels in endothelial cells during the injury phase. In the migration and proliferation stages, it can stimulate endothelial cell migration thereby upregulating growth factors, e.g., vascular growth factor, that promote angiogenesis (Li et al., 2016).

\section{NON-HEALING DIABETIC WOUNDS}

Diabetic wounds are known to heal with great difficulty, often resulting in ulcer formation. Furthermore, the injury size by a given insult is increased by diabetes (Palatinus and Gourdie, 2016). In non-healing wounds, $\mathrm{Cx} 43$ has been detected in wound margins in the vast majority of subjects, and at the periphery of wound site in all of the cases (Figure 4; Brandner et al., 2004). Some investigators have hypothesized that the cytoplasmic tail of Cx43 may bind to and interact with certain integral membrane and cytoskeletal proteins to modulate cell adhesion, cytoskeletal dynamics and ultimately, cell migration (Duffy et al., 2002; Gourdie et al., 2006; Becker et al., 2012).

Previous studies have demonstrated hyperglycaemia-induced, PKC-mediated Cx43 phosphorylation, leading to proteosomal degradation (Sato et al., 2002; Fernandes et al., 2004; Lin et al., 2006). It also depressed Cx43 gene expression and inhibited GJIC activity in cultured vascular smooth muscles. These changes were associated with alterations in connexin synthesis, phosphorylation, function and degradation. Prolonged hyperglycaemia resulted in damage to peritoneal mesothelial cells and impaired intercellular adhesion. The water soluble inducer of cellular differentiation, hexamethylene bisacetamide, reversed these pathological changes and upregulated gap junctions, thereby protecting peritoneal structural integrity (Ogawa et al., 2001). Previous studies on the relationship between $\mathrm{Cx} 43$ and diabetic vasculature have demonstrated a general trend of reduced $\mathrm{Cx} 43$ and depressed gap junction communication (Li et al., 2003; Makino et al., 2008). This was proposed to be 


\title{
Temporal and spatial patterns of connexins in chronic non-healing wounds
}

\author{
Event \\ $\mathrm{C} \times 26, \mathrm{C} \times 30$ \\ Pre-transplantation in Present at and near wound margins \\ human models and at some distance from wound \\ Present at and near wound margins \\ and at some distance from wound \\ Transplantation of cultured keratinocytes to porcine model \\ Post-transplantation Absent in transplanted keratinocytes \\ (7 hours) and at wound margins \\ Absent in transplanted keratinocytes \\ and at wound margins \\ Post-transplantation Present in some transplanted keratinocytes \\ (12-18 hours) and variable expression at wound margins \\ Weak and hetergenously found in few \\ transplanted keratinocytes \\ Absent at wound margins \\ Post-transplantation Present in all transplanted \\ Intense, heterogeneous expression in \\ (24 hours) keratinocytes and wound margins \\ all transplanted keratinocytes and at \\ wound margins \\ Incorporated from: \\ Connexins 26, 30, and 43: differences among spontaneous, chronic, and accelerated human \\ wound healing. Brandner JM(1), Houdek P, Hüsing B, Kaiser C, Moll I. Comment in J Invest \\ Dermatol. 2004 May;122(5):IX-X.
}

FIGURE 4 | Temporal and spatial patterns of connexins in chronic non-healing wounds Information derived from Brandner et al. (2004).

the pathological mechanism underlying the development of macroangiopathy in diabetic patients (Kuroki et al., 1998). Many studies have demonstrated a prolonged inflammatory phase in diabetic wounds, leading to a delay in granulation tissue formation and hence significantly delaying resolution (Mustoe, 2004; Wang et al., 2007; Dinh et al., 2012). Other studies have shown that in diabetic wounds, healing is arrested in the proliferative phase with an excess of matrix proteins, potentially resulting in non-healing wounds (Falanga, 2005).

Wound healing in diabetes has been studied further in streptozotocin-induced diabetic rats (Wang et al., 2007). In the diabetic state, Cx26 and Cx43 expression and communication in the intact epidermis were all reduced, whereas Cx43 was upregulated in the intact dermis. Connexin expression in wound healing also differed between diabetes and controls. Thus, Cx43 was upregulated in a thickened bulb of keratinocytes at the wound site within $24 \mathrm{~h}$, whereas it was downregulated in controls. The effects of Cx43-specific antisense gel have been tested on diabetic wounds by direct application, resulting in $\mathrm{Cx} 43$ upregulation and increased the rate of re-epithelialization.

The Cx43 mimetic peptide, $\alpha \mathrm{CT} 1$, was shown to significantly accelerate closure of diabetic foot ulcers and increase the incidence of complete closures (Grek et al., 2015). In this study, no adverse events or cases of immunogenicity were reported, suggesting that this agent could be safely applied in humans. However, the improvement in endpoints may partly be due to better compliance, since treatment was given in a study center on a weekly basis, compared to self-administration in previous studies (Margolis et al., 2002; Balingit et al., 2012; Grek et al.,
2015). A larger sample size will be needed in future studies along with increased diversity in terms of ethnicity and gender (Grek et al., 2015).

Another connexin 43 mimetic peptide, Gap27, was shown to enhance migration of keratinocytes and fibroblasts, accelerating wound healing in different mouse models (Pollok et al., 2011). Interestingly, there was a discrepancy in the responsiveness to Gap27 treatment between diabetic and non-diabetic cells (Pollok et al., 2011). Diabetic cells were immune to the migrationenhancing effects of Gap27. This may be related to a different microenvironment of the diabetic wound, such as hypoxia, the presence of pro-inflammatory mediators, high glucose levels together with an excess of matrix metalloproteinases (MMPs) relative to tissue inhibitors of MMPs (TIMPs) (Muller et al., 2008). These factors must therefore be considered when developing connexin modulator-based treatments to ensure their efficacy is not reduced (Pollok et al., 2011).

\section{PRESSURE ULCERS}

The National Pressure Ulcer Advisory Panel (NPUAP) defines a pressure ulcer as an area of unrelieved pressure over a defined area, usually over a bony prominence, resulting in ischemia, cell death, and tissue necrosis. More recent studies have shown that they can also be caused by ischaemia-reperfusion damage due to repeated pressure applied to the skin (Peirce et al., 2000). An in vitro model of ischemia-reperfusion injury in fibroblasts demonstrated increases in Cx43 levels, hemi-channel activity and 
cell death (Pringle et al., 1997). Gap27 exerted concentrationdependent effects: at high levels it significantly reduced $\mathrm{Cx} 43$ levels and GJIC, in turn reducing fibroblast cell death (Glass et al., 2015). In other studies, Gap27 was found to increase phosphorylation of S368 without altering the level of Cx43 (Evans and Boitano, 2001). It was suggested that Gap27 prevents the death of a number of cell types, including cardiomyocytes, cortical astrocytes and neurons, by blocking Cx43 opening during reperfusion (Thompson et al., 2006; Clarke et al., 2009; Orellana et al., 2010), as well as preventing "bystander effect" of cell death induction of healthy cells in close proximity (Mao et al., 2009; Danesh-Meyer et al., 2012; Zhang et al., 2013). Further investigations into the potential of Gap27 and other connexin modulators for clinical use will be the next step in improving treatment options for pressure ulcers.

\section{VENOUS LEG ULCERS}

Patients with chronic venous insufficiency are prone to the formation of venous leg ulcers. Impaired wound healing is attributed to continuous inflammation in extracellular matrix accompanied by fibroblast and keratinocyte dysfunction (Brandner et al., 2004; Charles et al., 2008; Ongstad et al., 2013; Kim et al., 2014). Current treatment protocol includes antiseptic use, wound dressing and limb compression (O'Meara et al., 2009). A randomized trial was conducted to investigate the beneficial effects of adding $\alpha \mathrm{CT} 1$ to the conventional treatment protocol (Ghatnekar et al., 2015). This approach significantly enhanced wound closure of the ulcers, resulting in a reduction of median healing time from 12 to 6 weeks compared to the standard treatment (Ghatnekar et al., 2015). However, there is limited information regarding prior treatments received, recurrence rate, and patient compliance (Ghatnekar et al., 2015). Therefore, further studies with a run-in period and an extended follow-up along with comparisons of different delivery vehicles are required to further establish the efficacy of $\alpha \mathrm{CT} 1$ in wound healing of venous leg ulcers (Ghatnekar et al., 2015).

\section{CORNEAL WOUND HEALING}

The corneal epithelium consists of four to six layers of nonkeratinized stratified squamous epithelial cells on a uniform basement membrane (Kenyon, 1979; DelMonte and Kim, 2011). Superficial cell layers have microvilli and microplicae for metabolite transportation and tear film adhesion, whereas the basal columnar layers are more metabolically active (Lu et al., 2001). At least eight Cx isoforms (Cx26, Cx30.3, Cx31, Cx31.1, $\mathrm{Cx} 32$, Cx43, Cx45, and $\mathrm{Cx} 50$ ) have been identified in the human corneal epithelium (Yuan et al., 2009; Zhai et al., 2014).

Corneal wound healing shares some similarities with skin healing (Moore et al., 2013). Epithelial healing starts with a non-mitotic wound coverage phase by cellular migration and spreading over the defect, followed by mitosis of epithelial cells (DelMonte and Kim, 2011). Stromal injuries induce migration and activation of keratocytes and subsequently stromal remodeling and fibrosis (Fini and Stramer, 2005). Endothelial trauma is resolved firstly by migration and coverage of adjacent endothelial cells, then return of normal tight junction function and lastly endothelial cell remodeling (Watsky et al., 1989; DelMonte and Kim, 2011). Pre-clinical experiments suggest that connexins play a role in corneal wound healing. In rabbit cornea after excimer laser photorefractive keratectomy, Cx43 and $\mathrm{Cx} 26$ were found to be upregulated (Ratkay-Traub et al., 2001). This is in corroboration with human findings where increased expressions of Cx26, Cx31.1, and Cx43 were detected in chemically burned and infected corneas (Zhai et al., 2014).

The commonest clinical method for cornea regeneration involves application of the amniotic membrane, although it has disadvantages such as donor dependent differences (Tsai et al., 2015). Other efforts have focused on the use of $\mathrm{Cx} 43$ mimetic peptides to promote corneal wound healing. Epithelialto-mesenchymal transition (EMT) is a cellular process involving mobilization of sedentary cells to areas needing repair (Leopold et al., 2012) and is thought to play a role in the cornea during healing (Lee et al., 2012; Kowtharapu et al., 2014). An extendedrelease preparation of $\alpha \mathrm{CT} 1$ using microcapsules was compared with a single high initial dose of $\alpha \mathrm{CT} 1$ or pluronic gel vehicle (Moore et al., 2013). Wound closure analysis showed that healing time was significantly reduced in rat cornea treated with $\alpha \mathrm{CT} 1$ microcapsule compared with other two regimes, showing a $14.55 \%$ improvement compared to pluronic gel treatment, while a single high $\alpha \mathrm{CT} 1$ dose resulted in only a $12.56 \%$ improvement. However, why $\alpha \mathrm{CT} 1$ treatment produced higher closure rate at $24-72 \mathrm{~h}$ even though the microencapsulated $\alpha \mathrm{CT} 1$ gives a higher percentage healing overall is unclear (Moore et al., 2013). Three different genes were analyzed with RT-PCR to study their short and long-term effects on corneal healing. Cx43 expression demonstrated a biphasic response, and was downregulated in $\alpha \mathrm{CT} 1$ treatments in day 21 , contrary to that in control group. ZO-1 was downregulated throughout the length of study for all set-ups. Keratin 19 (Krt19), a corneal epithelial progenitor and stemness marker gene that is thought to be downregulated during EMT, was significantly elevated after $24 \mathrm{~h}$ then downregulated in aCT1-treated cornea (Moore et al., 2013).

A later study by the same group examined the effects of the same $\alpha \mathrm{CT} 1$ preparations in type I diabetic corneal wound healing using a streptozotocin type 1 diabetic rat model (Moore et al., 2014). It was found that $\alpha \mathrm{CT} 1$, whether applied directly as pluronic gel solution or delivered in a sustained manner using microcapsules, accelerated wound closure significantly at days 1 and 3, with the latter producing the most rapid effects. The probability of wound healing rate calculated using a modified Kaplan-Meier method indicated that $\alpha \mathrm{CT} 1$, especially the microcapsule form, consistently improved corneal wound healing (Moore et al., 2014). The mechanism involves reduced inflammation as reflected by downregulation of the markers, Interferon Inducible T-Cell Alpha Chemoattractant and Tumor Necrosis Factor alpha markers (Moore et al., 2014). TGF- $\beta$ was the only gene upregulated throughout all time points. All three isoforms of TGF- $\beta$ are expressed in the cornea, and play a role in corneal development and wound healing (Jester et al., 1997; Saika, 2004). The effects of TGF- $\beta$ in suppressing inflammation, promoting fibroblast proliferative activity and ECM deposition 
are well-established (Carrington et al., 2006). These findings provide further evidence for the role of TGF- $\beta$ in corneal reepithelialisation, through induction of keratocyte transformation into fibroblasts during wound healing (Stramer et al., 2003). Krt19 level was again measured and initially downregulated followed by upregulation at later time points (Moore et al., 2014).

Moreover, Krt19 was negatively correlated to EMT (Aomatsu et al., 2011). It is not known whether the upregulations at initial and later stages were due to (1) artifacts; (2) an unknown underlying mechanism that may have caused an initial transient spike; or (3) hyperglycemia which may be responsible for inducing elevation of Krt19 level. Another study found that Snail gene overexpression during corneal wound healing induced upregulation of gap junction proteins (e.g., Cx43) and downregulation of stemness markers (e.g., Krt19) in mice (Aomatsu et al., 2012). The roles of Krt19 and Cx43 in differentiation and migration may provide further insight into the interplay between connexins and stemness markers in EMT. Based on the current evidence, it is suggested that the changes in phenotypic expression of stemness and differentiation markers in wounded corneal epithelium may be responsible for healing through EMT (Aomatsu et al., 2012). This could be achieved by arresting proliferation (Liu et al., 2010), remodeling of the cytoskeleton and enhancing migration (Thiery, 2002; Chen et al., 2004; Aomatsu et al., 2012). These four physiological processes may represent targets for modulating connexins to achieve therapeutic healing effects in the future.

\section{SUMMARY}

Connexins are ubiquitously expressed with tissue-specific subtypes. Their expression patterns in different diseases are now

\section{REFERENCES}

Alcoléa, S., Théveniau-Ruissy, M., Jarry-Guichard, T., Marics, I., Tzouanacou, E., Chauvin, J. P., et al. (1999). Downregulation of connexin 45 gene products during mouse heart development. Circ. Res. 84, 1365-1379.

Aomatsu, K., Arao, T., Abe, K., Kodama, A., Sugioka, K., Matsumoto, K., et al. (2012). Slug is upregulated during wound healing and regulates cellular phenotypes in corneal epithelial cells. Invest. Ophthalmol. Vis. Sci. 53, 751-756. doi: $10.1167 /$ iovs.11-8222

Aomatsu, K., Arao, T., Sugioka, K., Matsumoto, K., Tamura, D., Kudo, K., et al. (2011). TGF- $\beta$ induces sustained upregulation of SNAI1 and SNAI2 through Smad and non-Smad pathways in a human corneal epithelial cell line. Invest. Ophthalmol. Vis. Sci. 52, 2437-2443. doi: 10.1167/iovs.10-5635

Bajpai, S., Shukla, V. K., Tripathi, K., Srikrishna, S., and Singh, R. K. (2009). Targeting connexin 43 in diabetic wound healing: future perspectives. J. Postgrad. Med. 55, 143-149. doi: 10.4103/0022-3859.48786

Balingit, P. P., Armstrong, D. G., Reyzelman, A. M., Bolton, L., Verco, S. J., Rodgers, K. E., et al. (2012). NorLeu3-A(1-7) stimulation of diabetic foot ulcer healing: results of a randomized, parallel-group, double-blind, placebocontrolled phase 2 clinical trial. Wound Repair Regen. 20, 482-490. doi: 10.1111/ j.1524-475X.2012.00804.x

Bao, L., Sachs, F., and Dahl, G. (2004). Connexins are mechanosensitive. Am. J. Physiol. Cell Physiol. 287, C1389-C1395. doi: 10.1152/ajpcell.00220.2004

Becker, D. L., Thrasivoulou, C., and Phillips, A. R. (2012). Connexins in wound healing; perspectives in diabetic patients. Biochim. Biophys. Acta 1818, 2068-2075. doi: 10.1016/j.bbamem.2011.11.017 better characterized. Their ability to regulate immune responses, cell proliferation, migration and apoptosis makes them attractive therapeutic targets to promote the skin wound healing, diabetic and venous ulcers, as well as cornea healing. Novel approaches involve the use of antisense technology to reduce connexin expression, or synthetic mimetic peptides to reduce the function of connexins, which have demonstrated successes in pre-clinical disease models, with great potential in the future for clinical applications.

\section{AUTHOR CONTRIBUTIONS}

PW: Design of manuscript; drafted and critically revised the manuscript for important intellectual content; preparation of figures. TT: Drafted and critically revised the manuscript for important intellectual content. CC: Drafted and critically revised the manuscript for important intellectual content. VL: Drafted and critically revised the manuscript for important intellectual content. YC: Drafted and critically revised the manuscript for important intellectual content. TL: Critically revised the manuscript for important intellectual content. WW: Critically revised the manuscript for important intellectual content. GT: Design of manuscript; drafted and critically revised the manuscript for important intellectual content.

\section{ACKNOWLEDGMENTS}

GT received a BBSRC Doctoral Training Award at the University of Cambridge and thanks The Croucher Foundation for supporting his clinical assistant professorship. YC is supported by the ESRC for her research at the University of Cambridge.

Bennett, M. V., and Verselis, V. K. (1992). Biophysics of gap junctions. Semin. Cell Biol. 3, 29-47.

Beyer, E. C., and Berthoud, V. M. (2002). Gap junction synthesis and degradation as therapeutic targets. Curr. Drug Targets 3, 409-416. doi: 10.2174/ 1389450023347245

Brandner, J. M., Houdek, P., Husing, B., Kaiser, C., and Moll, I. (2004). Connexins 26, 30, and 43: differences among spontaneous, chronic, and accelerated human wound healing. J. Invest. Dermatol. 122, 1310-1320. doi: 10.1111/j.0022-202X. 2004.22529.x

Brissette, J. L., Kumar, N. M., Gilula, N. B., Hall, J. E., and Dotto, G. P. (1994). Switch in gap junction protein expression is associated with selective changes in junctional permeability during keratinocyte differentiation. Proc. Natl. Acad. Sci. U.S.A. 91, 6453-6457.

Budunova, I. V., Mittelman, L. A., and Miloszewska, J. (1994). Role of protein kinase $\mathrm{C}$ in the regulation of gap junctional communication. Teratog,. Carcinog. Mutagen. 14, 259-270.

Bukauskas, F. F., and Verselis, V. K. (2004). Gap junction channel gating. Biochim. Biophys. Acta 1662, 42-60. doi: 10.1016/j.bbamem.2004.01.008

Caputo, R., and Peluchetti, D. (1977). The junctions of normal human epidermis. A freeze-fracture study. J. Ultrastruct. Res. 61, 44-61.

Carrington, L. M., Albon, J., Anderson, I., Kamma, C., and Boulton, M. (2006). Differential regulation of key stages in early corneal wound healing by TGF- $\beta$ isoforms and their inhibitors. Invest. Ophthalmol. Vis. Sci. 47, 1886-1894. doi: 10.1167/iovs.05-0635

Charles, C. A., Tomic-Canic, M., Vincek, V., Nassiri, M., Stojadinovic, O., Eaglstein, W. H., et al. (2008). A gene signature of nonhealing venous ulcers: 
potential diagnostic markers. J. Am. Acad. Dermatol. 59, 758-771. doi: 10.1016/ j.jaad.2008.07.018

Chen, Z., de Paiva, C. S., Luo, L., Kretzer, F. L., Pflugfelder, S. C., and Li, D. Q. (2004). Characterization of putative stem cell phenotype in human limbal epithelia. Stem Cells 22, 355-366. doi: 10.1634/stemcells.22-3-355

Churko, J. M., and Laird, D. W. (2013). Gap junction remodeling in skin repair following wounding and disease. Physiology (Bethesda) 28, 190-198. doi: 10. 1152/physiol.00058.2012

Churko, J. M., Shao, Q., Gong, X. Q., Swoboda, K. J., Bai, D., Sampson, J., et al. (2011). Human dermal fibroblasts derived from oculodentodigital dysplasia patients suggest that patients may have wound-healing defects. Hum. Mutat. 32, 456-466. doi: 10.1002/humu.21472

Clarke, T. C., Williams, O. J., Martin, P. E., and Evans, W. H. (2009). ATP release by cardiac myocytes in a simulated ischaemia model: inhibition by a connexin mimetic and enhancement by an antiarrhythmic peptide. Eur. J. Pharmacol. 605, 9-14. doi: 10.1016/j.ejphar.2008.12.005

Coutinho, P., Qiu, C., Frank, S., Tamber, K., and Becker, D. (2003). Dynamic changes in connexin expression correlate with key events in the wound healing process. Cell Biol. Int. 27, 525-541. doi: 10.1016/S1065-6995(03)00077-5

Crespo Yanguas, S., Willebrords, J., Maes, M., da Silva, T. C., Veloso Alves Pereira, I., Cogliati, B., et al. (2016). Connexins and pannexins in liver damage. EXCLI J. 15, 177-186. doi: 10.17179/excli2016-119

Danesh-Meyer, H. V., Kerr, N. M., Zhang, J., Eady, E. K., O'Carroll, S. J., Nicholson, L. F., et al. (2012). Connexin43 mimetic peptide reduces vascular leak and retinal ganglion cell death following retinal ischaemia. Brain 135, 506-520. doi: 10.1093/brain/awr338

Davis, L. M., Rodefeld, M. E., Green, K., Beyer, E. C., and Saffitz, J. E. (1995). Gap junction protein phenotypes of the human heart and conduction system. J. Cardiovasc. Electrophysiol. 6, 813-822.

DelMonte, D. W., and Kim, T. (2011). Anatomy and physiology of the cornea. J. Cataract Refract. Surg. 37, 588-598. doi: 10.1016/j.jcrs.2010.12.037

Desplantez, T., Verma, V., Leybaert, L., Evans, W. H., and Weingart, R. (2012). Gap26, a connexin mimetic peptide, inhibits currents carried by connexin 43 hemichannels and gap junction channels. Pharmacol. Res. 65, 546-552. doi: 10. 1016/j.phrs.2012.02.002

Dinh, T., Tecilazich, F., Kafanas, A., Doupis, J., Gnardellis, C., Leal, E., et al. (2012). Mechanisms involved in the development and healing of diabetic foot ulceration. Diabetes 61, 2937-2947. doi: 10.2337/db12-0227

Dovi, J. V., He, L. K., and DiPietro, L. A. (2003). Accelerated wound closure in neutrophil-depleted mice. J. Leukoc. Biol. 73, 448-455. doi: 10.1189/jlb.0802406

Duffy, H. S., Delmar, M., and Spray, D. C. (2002). Formation of the gap junction nexus: binding partners for connexins. J. Physiol. Paris 96, 243-249. doi: 10. 1016/S0928-4257(02)00012-8

Esseltine, J. L., Shao, Q., Huang, T., Kelly, J. J., Sampson, J., and Laird, D. W. (2015). Manipulating Cx43 expression triggers gene reprogramming events in dermal fibroblasts from oculodentodigital dysplasia patients. Biochem. J. 472, 55-69. doi: 10.1042/BJ20150652

Evans, W. H., and Boitano, S. (2001). Connexin mimetic peptides: specific inhibitors of gap-junctional intercellular communication. Biochem. Soc. Trans. 29, 606-612. doi: 10.1042/bst0290606

Evans, W. H., De Vuyst, E., and Leybaert, L. (2006). The gap junction cellular internet: connexin hemichannels enter the signalling limelight. Biochem. J. 397, 1-14. doi: 10.1042/BJ20060175

Falanga, V. (2005). Wound healing and its impairment in the diabetic foot. Lancet 366, 1736-1743. doi: 10.1016/S0140-6736(05)67700-8

Fernandes, R., Girão, H., and Pereira, P. (2004). High glucose downregulates intercellular communication in retinal endothelial cells by enhancing degradation of connexin 43 by a proteasome-dependent mechanism. J. Biol. Chem. 279, 27219-27224. doi: 10.1074/jbc.M400446200

Fini, M. E., and Stramer, B. M. (2005). How the cornea heals: cornea-specific repair mechanisms affecting surgical outcomes. Cornea 24, S2-S11. doi: 10.1097/01. ico.0000178743.06340.2c

Froger, N., Orellana, J. A., Calvo, C. F., Amigou, E., Kozoriz, M. G., Naus, C. C., et al. (2010). Inhibition of cytokine-induced connexin 43 hemichannel activity in astrocytes is neuroprotective. Mol. Cell. Neurosci. 45, 37-46. doi: 10.1016/j. mcn.2010.05.007

Ghatnekar, G. S., Grek, C. L., Armstrong, D. G., Desai, S. C., and Gourdie, R. G. (2015). The effect of a connexin43-based Peptide on the healing of chronic venous leg ulcers: a multicenter, randomized trial. J. Invest. Dermatol. 135, 289-298. doi: 10.1038/jid.2014.318

Ghatnekar, G. S., O'Quinn, M. P., Jourdan, L. J., Gurjarpadhye, A. A., Draughn, R. L., and Gourdie, R. G. (2009). Connexin43 carboxyl-terminal peptides reduce scar progenitor and promote regenerative healing following skin wounding. Regen. Med. 4, 205-223. doi: 10.2217/17460751.4.2.205

Giese, S., Hossain, H., Markmann, M., Chakraborty, T., Tchatalbachev, S., Guillou, F., et al. (2012). Sertoli-cell-specific knockout of connexin 43 leads to multiple alterations in testicular gene expression in prepubertal mice. Dis. Model. Mech. 5, 895-913. doi: 10.1242/dmm.008649

Glass, B. J., Hu, R. G., Phillips, A. R., and Becker, D. L. (2015). The action of mimetic peptides on connexins protects fibroblasts from the negative effects of ischemia reperfusion. Biol. Open 4, 1473-1480. doi: 10.1242/bio.013573

Goldberg, G. S., Valiunas, V., and Brink, P. R. (2004). Selective permeability of gap junction channels. Biochim. Biophys. Acta 1662, 96-101. doi: 10.1016/j. bbamem.2003.11.022

Goliger, J. A., and Paul, D. L. (1995). Wounding alters epidermal connexin expression and gap junction-mediated intercellular communication. Mol. Biol. Cell 6, 1491-1501.

Gourdie, R. G., Ghatnekar, G. S., O’Quinn, M., Rhett, M. J., Barker, R. J., Zhu, C., et al. (2006). The unstoppable connexin 43 carboxyl-terminus: new roles in gap junction organization and wound healing. Ann. N.Y. Acad. Sci. 1080, 49-62. doi: 10.1196/annals.1380.005

Grek, C. L., Prasad, G. M., Viswanathan, V., Armstrong, D. G., Gourdie, R. G., and Ghatnekar, G. S. (2015). Topical administration of a connexin43-based peptide augments healing of chronic neuropathic diabetic foot ulcers: a multicenter, randomized trial. Wound Repair Regen. 23, 203-212. doi: 10.1111/wrr.12275

Grek, C. L., Rhett, J. M., and Ghatnekar, G. S. (2014). Cardiac to cancer: connecting connexins to clinical opportunity. FEBS Lett. 588, 1349-1364. doi: 10.1016/j. febslet.2014.02.047

Guo, S., and Dipietro, L. A. (2010). Factors affecting wound healing. J. Dent. Res. 89, 219-229. doi: 10.1177/0022034509359125

Harris, A. L. (2001). Emerging issues of connexin channels: biophysics fills the gap. Q. Rev. Biophys. 34, 325-472. doi: 10.1017/S0033583501003705

Jester, J. V., Barry-Lane, P. A., Petroll, W. M., Olsen, D. R., and Cavanagh, H. D. (1997). Inhibition of corneal fibrosis by topical application of blocking antibodies to TGF $\beta$ in the rabbit. Cornea 16, 177-187.

Jin, E. J., Lee, S. Y., Jung, J. C., Bang, O. S., and Kang, S. S. (2008). TGF$\beta 3$ inhibits chondrogenesis of cultured chick leg bud mesenchymal cells via downregulation of connexin 43 and integrin beta4. J. Cell. Physiol. 214, 345-353. doi: $10.1002 / j c p .21202$

Jongsma, H. J. (2000). Diversity of gap junctional proteins: does it play a role in cardiac excitation? J. Cardiovasc. Electrophysiol. 11, 228-230. doi: 10.1111/j. 1540-8167.2000.tb00325.x

Kanno, Y., and Loewenstein, W. R. (1964). Low-resistance coupling between Gland Cells. Some observations on intercellular contact membranes and intercellular space. Nature 201, 194-195.

Ke, Q., Li, L., Cai, B., Liu, C., Yang, Y., Gao, Y., et al. (2013). Connexin 43 is involved in the generation of human-induced pluripotent stem cells. Hum. Mol. Genet. 22, 2221-2233. doi: 10.1093/hmg/ddt074

Kenyon, K. R. (1979). Anatomy and pathology of the ocular surface. Int. Ophthalmol. Clin. 19, 3-35.

Kim, M. H., Gorouhi, F., Ramirez, S., Granick, J. L., Byrne, B. A., Soulika, A. M., et al. (2014). Catecholamine stress alters neutrophil trafficking and impairs wound healing by beta2-adrenergic receptor-mediated upregulation of IL-6. J. Invest. Dermatol. 134, 809-817. doi: 10.1038/jid.2013.415

Kirschner, N., and Brandner, J. M. (2012). Barriers and more: functions of tight junction proteins in the skin. Ann. N.Y. Acad. Sci. 1257, 158-166. doi: 10.1111/ j.1749-6632.2012.06554.x

Koval, M., Isakson, B. E., and Gourdie, R. G. (2014). Connexins, pannexins and innexins: protein cousins with overlapping functions. FEBS Lett. 588, 1185. doi: 10.1016/j.febslet.2014.03.001

Kowtharapu, B. S., Stahnke, T., Wree, A., Guthoff, R. F., and Stachs, O. (2014). Corneal epithelial and neuronal interactions: role in wound healing. Exp. Eye Res. 125, 53-61. doi: 10.1016/j.exer.2014.05.006

Kretz, M., Euwens, C., Hombach, S., Eckardt, D., Teubner, B., Traub, O., et al. (2003). Altered connexin expression and wound healing in the epidermis of connexin-deficient mice. J. Cell Sci. 116, 3443-3452. doi: 10.1242/jcs.00638 
Kuroki, T., Inoguchi, T., Umeda, F., Ueda, F., and Nawata, H. (1998). High glucose induces alteration of gap junction permeability and phosphorylation of connexin-43 in cultured aortic smooth muscle cells. Diabetes 47, 931-936.

Lampe, P. D., TenBroek, E. M., Burt, J. M., Kurata, W. E., Johnson, R. G., and Lau, A. F. (2000). Phosphorylation of connexin 43 on serine 368 by protein kinase $C$ regulates gap junctional communication. J. Cell Biol. 149, 1503-1512. doi: 10. 1083/jcb.149.7.1503

Lawrence, T. S., Beers, W. H., and Gilula, N. B. (1978). Transmission of hormonal stimulation by cell-to-cell communication. Nature 272, 501-506.

Lee, J. G., Ko, M. K., and Kay, E. P. (2012). Endothelial mesenchymal transformation mediated by IL-1beta-induced FGF-2 in corneal endothelial cells. Exp. Eye Res. 95, 35-39. doi: 10.1016/j.exer.2011.08.003

Leopold, P. L., Vincent, J., and Wang, H. (2012). A comparison of epithelialto-mesenchymal transition and re-epithelialization. Semin. Cancer Biol. 22, 471-483. doi: 10.1016/j.semcancer.2012.07.003

Li, A. F., Sato, T., Haimovici, R., Okamoto, T., and Roy, S. (2003). High glucose alters connexin 43 expression and gap junction intercellular communication activity in retinal pericytes. Invest. Ophthalmol. Vis. Sci. 44, 5376-5382. doi: 10. 1167/iovs.03-0360

Li, H., He, J., Yu, H., Green, C. R., and Chang, J. (2016). Bioglass promotes wound healing by affecting gap junction connexin 43 mediated endothelial cell behavior. Biomaterials 84, 64-75. doi: 10.1016/j.biomaterials.2016.01.033

Lin, H., Ogawa, K., Imanaga, I., and Tribulova, N. (2006). Alterations of connexin 43 in the diabetic rat heart. Adv. Cardiol. 42, 243-254. doi: 10.1159/000092573

Lin, R., Warn-Cramer, B. J., Kurata, W. E., and Lau, A. F. (2001). v-Src phosphorylation of connexin 43 on Tyr247 and Tyr265 disrupts gap junctional communication. J. Cell Biol. 154, 815-827. doi: 10.1083/jcb.200102027

Liu, J., Uygur, B., Zhang, Z., Shao, L., Romero, D., Vary, C., et al. (2010). Slug inhibits proliferation of human prostate cancer cells via downregulation of cyclin D1 expression. Prostate 70, 1768-1777. doi: 10.1002/pros.21213

Lu, L., Reinach, P. S., and Kao, W. W. (2001). Corneal epithelial wound healing. Exp. Biol. Med. (Maywood). 226, 653-664.

Lucke, T., Choudhry, R., Thom, R., Selmer, I. S., Burden, A. D., and Hodgins, M. B. (1999). Upregulation of connexin 26 is a feature of keratinocyte differentiation in hyperproliferative epidermis, vaginal epithelium, and buccal epithelium. $J$. Invest. Dermatol. 112, 354-361. doi: 10.1046/j.1523-1747.1999.00512.x

Makino, A., Platoshyn, O., Suarez, J., Yuan, J. X., and Dillmann, W. H. (2008). Downregulation of connexin 40 is associated with coronary endothelial cell dysfunction in streptozotocin-induced diabetic mice. Am. J. Physiol. Cell Physiol. 295, C221-C230. doi: 10.1152/ajpcell.00433.2007

Mao, H. J., Chen, B. P., Yu, T. N., Ye, Z. G., Yuan, X. G., and Xia, Q. (2009). [Effect of gap junction on the cardioprotection of ischemic postconditioning in rat heart]. Zhongguo Ying Yong Sheng Li Xue Za Zhi 25, 60-64.

Margolis, D. J., Allen-Taylor, L., Hoffstad, O., and Berlin, J. A. (2002). Diabetic neuropathic foot ulcers: the association of wound size, wound duration, and wound grade on healing. Diabetes Care 25, 1835-1839. doi: 10.2337/diacare.25. 10.1835

Márquez-Rosado, L., Solan, J. L., Dunn, C. A., Norris, R. P., and Lampe, P. D. (2012). Connexin 43 phosphorylation in brain, cardiac, endothelial and epithelial tissues. Biochim. Biophys. Acta 1818, 1985-1992. doi: 10.1016/j. bbamem.2011.07.028

Mendoza-Naranjo, A., Cormie, P., Serrano, A. E., Hu, R., O’Neill, S., Wang, C. M., et al. (2012). Targeting Cx43 and N-cadherin, which are abnormally upregulated in venous leg ulcers, influences migration, adhesion and activation of Rho GTPases. PLoS ONE 7:e37374. doi: 10.1371/journal.pone.0037374

Meyer, R. A., Lampe, P. D., Malewicz, B., Baumann, W. J., and Johnson, R. G. (1991). Enhanced gap junction formation with LDL and apolipoprotein B. Exp. Cell Res. 196, 72-81.

Meyer, R., Malewicz, B., Baumann, W. J., and Johnson, R. G. (1990). Increased gap junction assembly between cultured cells upon cholesterol supplementation. J. Cell Sci. 96 (Pt 2), 231-238.

Moore, K., Bryant, Z. J., Ghatnekar, G., Singh, U. P., Gourdie, R. G., and Potts, J. D. (2013). A synthetic connexin 43 mimetic peptide augments corneal wound healing. Exp. Eye Res. 115, 178-188. doi: 10.1016/j.exer.2013.07.001

Moore, K., Ghatnekar, G., Gourdie, R. G., and Potts, J. D. (2014). Impact of the controlled release of a connexin 43 peptide on corneal wound closure in an STZ model of type I diabetes. PLoS ONE 9:e86570. doi: 10.1371/journal.pone. 0086570
Mori, R., Power, K. T., Wang, C. M., Martin, P., and Becker, D. L. (2006). Acute downregulation of connexin 43 at wound sites leads to a reduced inflammatory response, enhanced keratinocyte proliferation and wound fibroblast migration. J. Cell Sci. 119, 5193-5203. doi: $10.1242 /$ jcs. 03320

Muller, M., Trocme, C., Lardy, B., Morel, F., Halimi, S., and Benhamou, P. Y. (2008). Matrix metalloproteinases and diabetic foot ulcers: the ratio of MMP-1 to TIMP-1 is a predictor of wound healing. Diabet. Med. 25, 419-426. doi: 10 . $1111 /$ j.1464-5491.2008.02414.x

Musil, L. S., and Goodenough, D. A. (1991). Biochemical analysis of connexin43 intracellular transport, phosphorylation, and assembly into gap junctional plaques. J. Cell Biol. 115, 1357-1374.

Mustoe, T. (2004). Understanding chronic wounds: a unifying hypothesis on their pathogenesis and implications for therapy. Am. J. Surg. 187, 65S-70S. doi: 10. 1016/S0002-9610(03)00306-4

O'Carroll, S. J., Becker, D. L., Davidson, J. O., Gunn, A. J., Nicholson, L. F., and Green, C. R. (2013). The use of connexin-based therapeutic approaches to target inflammatory diseases. Methods Mol. Biol. 1037, 519-546. doi: 10.1007/978-162703-505-7_31

Ogawa, T., Hayashi, T., Yorioka, N., Kyoizumi, S., and Trosko, J. E. (2001). Hexamethylene bisacetamide protects peritoneal mesothelial cells from glucose. Kidney Int. 60, 996-1008. doi: 10.1046/j.1523-1755.2001.060003 996.x

O'Meara, S., Cullum, N. A., and Nelson, E. A. (2009). Compression for venous leg ulcers. Cochrane Database Syst Rev. 2009:CD000265. doi: 10.1002/14651858. CD000265.pub2

Ongstad, E. L., O'Quinn, M. P., Ghatnekar, G. S., Yost, M. J., and Gourdie, R. G. (2013). A Connexin 43 mimetic peptide promotes regenerative healing and improves mechanical properties in skin and heart. Adv. Wound Care (New Rochelle) 2, 55-62. doi: 10.1089/wound.2011.0341

Orellana, J. A., Hernandez, D. E., Ezan, P., Velarde, V., Bennett, M. V., Giaume, C., et al. (2010). Hypoxia in high glucose followed by reoxygenation in normal glucose reduces the viability of cortical astrocytes through increased permeability of connexin 43 hemichannels. Glia 58, 329-343. doi: 10.1002/glia. 20926

Palatinus, J. A., and Gourdie, R. G. (2016). Diabetes increases cryoinjury size with associated effects on $\mathrm{Cx} 43$ gap junction function and phosphorylation in the mouse heart. J. Diabetes Res. 2016:8789617. doi: 10.1155/2016/8789617

Peirce, S. M., Skalak, T. C., and Rodeheaver, G. T. (2000). Ischemiareperfusion injury in chronic pressure ulcer formation: a skin model in the rat. Wound Repair Regen. 8, 68-76. doi: 10.1046/j.1524-475x.2000. 00068.x

Plum, A., Hallas, G., Magin, T., Dombrowski, F., Hagendorff, A., Schumacher, B., et al. (2000). Unique and shared functions of different connexins in mice. Curr. Biol. 10, 1083-1091. doi: 10.1016/S0960-9822(00)00690-4

Pollok, S., Pfeiffer, A. C., Lobmann, R., Wright, C. S., Moll, I., Martin, P. E., et al. (2011). Connexin 43 mimetic peptide Gap27 reveals potential differences in the role of $\mathrm{Cx} 43$ in wound repair between diabetic and non-diabetic cells. J. Cell. Mol. Med. 15, 861-873. doi: 10.1111/j.1582-4934.2010.01057.x

Presley, C. A., Lee, A. W., Kastl, B., Igbinosa, I., Yamada, Y., Fishman, G. I., et al. (2005). Bone marrow connexin-43 expression is critical for hematopoietic regeneration after chemotherapy. Cell Commun. Adhes. 12, 307-317. doi: 10. $1080 / 15419060500514200$

Pringle, A. K., Iannotti, F., Wilde, G. J., Chad, J. E., Seeley, P. J., and Sundstrom, L. E. (1997). Neuroprotection by both NMDA and non-NMDA receptor antagonists in in vitro ischemia. Brain Res. 755, 36-46.

Qiu, C., Coutinho, P., Frank, S., Franke, S., Law, L. Y., Martin, P., et al. (2003). Targeting connexin 43 expression accelerates the rate of wound repair. Curr. Biol. 13, 1697-1703. doi: 10.1016/j.cub.2003.09.007

Ratkay-Traub, I., Hopp, B., Bor, Z., Dux, L., Becker, D. L., and Krenacs, T. (2001). Regeneration of rabbit cornea following excimer laser photorefractive keratectomy: a study on gap junctions, epithelial junctions and epidermal growth factor receptor expression in correlation with cell proliferation. Exp. Eye Res. 73, 291-302. doi: 10.1006/exer.2001.1040

Richards, T. S., Dunn, C. A., Carter, W. G., Usui, M. L., Olerud, J. E., and Lampe, P. D. (2004). Protein kinase C spatially and temporally regulates gap junctional communication during human wound repair via phosphorylation of connexin43 on serine368. J. Cell Biol. 167, 555-562. doi: 10.1083/jcb.2004 04142 
Rossi, D., and Zlotnik, A. (2000). The biology of chemokines and their receptors. Annu. Rev. Immunol. 18, 217-242. doi: 10.1146/annurev.immunol.18.1.217

Saika, S. (2004). TGF- $\beta$ signal transduction in corneal wound healing as a therapeutic target. Cornea 23, S25-S30. doi: 10.1097/01.ico.0000136668. 41000.73

Sato, T., Haimovici, R., Kao, R., Li, A. F., and Roy, S. (2002). Downregulation of connexin 43 expression by high glucose reduces gap junction activity in microvascular endothelial cells. Diabetes 51, 1565-1571. doi: 10.2337/diabetes. 51.5.1565

Scott, C. A., Tattersall, D., O’Toole, E. A., and Kelsell, D. P. (2012). Connexins in epidermal homeostasis and skin disease. Biochim. Biophys. Acta 1818, 1952-1961. doi: 10.1016/j.bbamem.2011.09.004

Singh, D., Solan, J. L., Taffet, S. M., Javier, R., and Lampe, P. D. (2005). Connexin 43 Interacts with Zona Occludens-1 and -2 Proteins in a Cell Cycle Stage-specific Manner. J. Biol. Chem. 280, 30416-30421. doi: 10.1074/jbc.M506799200

Soder, B. L., Propst, J. T., Brooks, T. M., Goodwin, R. L., Friedman, H. I., Yost, M. J., et al. (2009). The connexin 43 carboxyl-terminal peptide ACT1 modulates the biological response to silicone implants. Plast. Reconstr. Surg. 123, 1440-1451. doi: 10.1097/PRS.0b013e3181a0741d

Söhl, G., and Willecke, K. (2004). Gap junctions and the connexin protein family. Cardiovasc. Res. 62, 228-232. doi: 10.1016/j.cardiores.2003.11.013

Solan, J. L., Fry, M. D., TenBroek, E. M., and Lampe, P. D. (2003). Connexin43 phosphorylation at $\mathrm{S} 368$ is acute during $\mathrm{S}$ and G2/M and in response to protein kinase C activation. J. Cell Sci. 116, 2203-2211. doi: 10.1242/jcs.00428

Solan, J. L., and Lampe, P. D. (2014). Specific Cx43 phosphorylation events regulate gap junction turnover in vivo. FEBS Lett. 588, 1423-1429. doi: 10.1016/j.febslet. 2014.01.049

Stramer, B. M., Zieske, J. D., Jung, J. C., Austin, J. S., and Fini, M. E. (2003). Molecular mechanisms controlling the fibrotic repair phenotype in cornea: implications for surgical outcomes. Invest. Ophthalmol. Vis. Sci. 44, 4237-4246. doi: $10.1167 /$ iovs. $02-1188$

Thiery, J. P. (2002). Epithelial-mesenchymal transitions in tumour progression. Nat. Rev. Cancer 2, 442-454. doi: 10.1038/nrc822

Thompson, R. J., Zhou, N., and MacVicar, B. A. (2006). Ischemia opens neuronal gap junction hemichannels. Science 312, 924-927. doi: 10.1126/science.1126241

Tsai, I. L., Hsu, C.-C., Hung, K.-H., Chang, C.-W., and Cheng, Y.-H. (2015). Applications of biomaterials in corneal wound healing. J. Chin. Med. Assoc. 78, 212-217. doi: 10.1016/j.jcma.2014.09.011

Tse, G. (2016). Both transmural dispersion of repolarization and of refractoriness are poor predictors of arrhythmogenicity: a role for $\mathrm{iCEB}(\mathrm{QT} / \mathrm{QRS})$ ? J. Geriatr. Cardiol. 13, 813-814. doi: 10.11909/j.issn.1671-5411.2016.09.007

Tse, G., Lai, E. T. H., Yeo, J. M., Tse, V., and Wong, S. H. (2016a). Mechanisms of electrical activation and conduction in the gastrointestinal system: lessons from cardiac electrophysiology. Front. Physiol. 7:182. doi: 10.3389/fphys.2016.00182

Tse, G., Sun, B., Wong, S. T., Tse, V., and Yeo, J. M. (2016b). Ventricular antiarrhythmic effects of hypercalcaemia treatment in hyperkalaemic, Langendorffperfused mouse hearts. Biomed Rep. 5, 301-310. doi: 10.3892/br.2016.735

Tse, G., Tse, V., and Yeo, J. M. (2016c). Ventricular anti-arrhythmic effects of heptanol in hypokalaemic, Langendorff-perfused mouse hearts. Biomed Rep. 4, 313-324. doi: 10.3892/br.2016.577

Tse, G., Tse, V., Yeo, J. M., and Sun, B. (2016d). Atrial anti-arrhythmic effects of heptanol in Langendorff-perfused mouse hearts. PLoS ONE 11:e0148858. doi: 10.1371 /journal.pone. 0148858

Tse, G., Wong, S. T., Tse, V., and Yeo, J. M. (2016e). Restitution analysis of alternans using dynamic pacing and its comparison with S1S2 restitution in heptanol-treated, hypokalaemic Langendorff-perfused mouse hearts. Biomed. Rep. 4, 673-680. doi: 10.3892/br.2016.659

Tse, G., and Yeo, J. M. (2015). Conduction abnormalities and ventricular arrhythmogenesis: the roles of sodium channels and gap junctions. Int. J. Cardiol. Heart Vasc. 9, 75-82. doi: 10.1016/j.ijcha.2015.10.003
Tse, G., Yeo, J. M., Tse, V., Kwan, J., and Sun, B. (2016f). Gap junction inhibition by heptanol increases ventricular arrhythmogenicity by decreasing conduction velocity without affecting repolarization properties or myocardial refractoriness in Langendorff-perfused mouse hearts. Mol. Med. Rep. 14, 4069-4074. doi: 10.3892/mmr. 2016.5738

Veeraraghavan, R., Gourdie, R. G., and Poelzing, S. (2014). Mechanisms of cardiac conduction: a history of revisions. Am. J. Physiol. Heart Circ. Physiol. 306, H619-H627. doi: 10.1152/ajpheart.007 60.2013

Veeraraghavan, R., Lin, J., Hoeker, G. S., Keener, J. P., Gourdie, R. G., and Poelzing, S. (2015). Sodium channels in the $\mathrm{Cx} 43$ gap junction perinexus may constitute a cardiac ephapse: an experimental and modeling study. Pflugers Arch. 467, 2093-2105. doi: 10.1007/s00424-014-1675-z

Wang, C. M., Lincoln, J., Cook, J. E., and Becker, D. L. (2007). Abnormal connexin expression underlies delayed wound healing in diabetic skin. Diabetes 56, 2809-2817. doi: 10.2337/db07-0613

Wang, X., Ramirez, A., and Budunova, I. (2010). Overexpression of connexin26 in the basal keratinocytes reduces sensitivity to tumor promoter TPA. Exp. Dermatol. 19, 633-640. doi: 10.1111/j.1600-0625.2009. 01013.x

Watsky, M. A., McDermott, M. L., and Edelhauser, H. F. (1989). In vitro corneal endothelial permeability in rabbit and human: the effects of age, cataract surgery and diabetes. Exp. Eye Res. 49, 751-767.

Wilgenbus, K. K., Kirkpatrick, C. J., Knuechel, R., Willecke, K., and Traub, O. (1992). Expression of Cx26, Cx32 and Cx43 gap junction proteins in normal and neoplastic human tissues. Int. J. Cancer 51, 522-529.

Wiszniewski, L., Limat, A., Saurat, J. H., Meda, P., and Salomon, D. (2000). Differential expression of connexins during stratification of human keratinocytes. J. Invest. Dermatol. 115, 278-285. doi: 10.1046/j.1523-1747.2000. 00043.x

Yuan, X., Chen, Z., Yang, Z., Gao, J., Zhang, A., Wu, S. M., et al. (2009). Expression pattern of connexins in the corneal and limbal epithelium of a primate. Cornea 28, 194-199. doi: 10.1097/ICO.0b013e318185268e

Zhai, J., Wang, Q. I. N., and Tao, L. (2014). Connexin expression patterns in diseased human corneas. Exp. Ther. Med. 7, 791-798. doi: 10.3892/etm. 2014.1530

Zhang, L., Li, Y. M., Jing, Y. H., Wang, S. Y., Song, Y. F., and Yin, J. (2013). Protective effects of carbenoxolone are associated with attenuation of oxidative stress in ischemic brain injury. Neurosci. Bull. 29, 311-320. doi: 10.1007/ s12264-013-1342-y

Zhou, J. Z., and Jiang, J. X. (2014). Gap junction and hemichannel-independent actions of connexins on cell and tissue functions-an update. FEBS Lett. 588, 1186-1192. doi: 10.1016/j.febslet.2014.01.001

Conflict of Interest Statement: The authors declare that the research was conducted in the absence of any commercial or financial relationships that could be construed as a potential conflict of interest.

The reviewer MT and handling Editor declared their shared affiliation, and the handling Editor states that the process nevertheless met the standards of a fair and objective review.

Copyright (๑) 2016 Wong, Tan, Chan, Laxton, Chan, Liu, Wong and Tse. This is an open-access article distributed under the terms of the Creative Commons Attribution License (CC BY). The use, distribution or reproduction in other forums is permitted, provided the original author(s) or licensor are credited and that the original publication in this journal is cited, in accordance with accepted academic practice. No use, distribution or reproduction is permitted which does not comply with these terms. 